\title{
CONCEPÇÕES DE FORMAÇÃO NO CURSO DE PEDAGOGIA
}

\author{
Training conceptions in the Pedagogy course \\ Concepciones de formación en el curso de Pedagogía \\ Renata Loiza Alcântara Soares* \\ Viviane de Souza Rodrigues**
}

https://doi.org/10.38117/2675-181X.formov2021.v3i1n5.345-357.

\begin{abstract}
Resumo
Com a criação das Diretrizes Curriculares Nacionais no ano de 2006 (Resolução CNE/CP $\left.\mathrm{n}^{\mathrm{o}} 1 / 2006\right)$ para o curso de Pedagogia, criou-se novo debate sobre a abrangência dessa proposta e suas consequências em torno da identidade do curso. Esse trabalho tem como objetivo realizar uma análise dos principais aspectos que conformam a trajetória política do curso de Pedagogia, a partir de uma pesquisa de abordagem qualitativa, por meio de revisão de literatura e pesquisa documental. $\mathrm{O}$ artigo parte de um panorama histórico e conceitual do cenário da Pedagogia, que representa um processo de disputas com avanços e retrocessos no sistema educacional. Busca-se apontar questões sobre a política curricular enquanto preocupação estratégica na identidade e formação profissional, particularmente, através das mais recentes normativas que incidem em novas adaptações curriculares, acumulando incertezas no campo da Pedagogia enquanto ciência e dualidades na formação profissional.
\end{abstract}

Palavras-chave: Política Educacional; Curso de Pedagogia; Concepções de Formação.

\begin{abstract}
With the creation of the National Curriculum Guidelines in 2006 (Resolution CNE/CP n ${ }^{\circ}$ $1 / 2006$ ) for the Pedagogy course, a new discussion was created about the scope of this proposal and its consequences around the identity of the course. This work aims to carry out an analysis of the main aspects that make up the political trajectory of the Pedagogy course, based on a qualitative research, through literature review and documentary research. The article starts from a historical and conceptual panorama of the Pedagogy scenario, which represents a process of
\end{abstract}


disputes with advances and setbacks in the educational system. It seeks to point out issues about curricular policy as a strategic concern in identity and professional training, particularly, through the most recent regulations that affect new curricular adaptations, accumulating uncertainties in the field of Pedagogy as science and dualities in professional training.

Keywords: Educational Policy; Pedagogy Course; Training Conceptions.

\section{Resumen}

Con la creación de los Lineamientos Curriculares Nacionales en 2006 (Resolución CNE/CP $\mathrm{N}^{\circ}$ 1/2006) para el curso de Pedagogía, se generó nuevo debate sobre los alcances de esta propuesta y sus consecuencias en torno a la identidad del curso. Este trabajo tiene como objetivo realizar un análisis de los principales aspectos que componen la trayectoria política del curso de Pedagogía, a partir de una investigación cualitativa, a través de la revisión de la literatura y la investigación documental. El artículo parte de un panorama histórico y conceptual deles cenário Pedagógico, que representa un proceso de disputas con avances y retrocesos y nel sistema educativo. Busca señalar cuestiones sobre la política curricular como una preocupación estratégica en la identidad y La formación profesional, en particular, a través de las normativas más recientes que inciden em nuevas adaptaciones curriculares, acumulando incertidumbres en el campo de la Pedagogía como ciencia y dualidades em la formación profesional.

Palabras clave: Política Educativa; Curso de Pedagogía; Concepciones de Formación.

\section{Introdução}

O campo de formação de professores acumula em seu processo histórico avanços e retrocessos, modelos que por mediação de ideologias hegemônicas, geraram desvalorização da categoria, esvaziamento de conhecimentos, aligeiramento e mercantilização da educação brasileira. As Diretrizes e Bases da Educação Nacional, lei $\mathrm{n}^{\text {o }}$ 9.394/1996 (LDBEN), mesmo promulgada em meio às tendências da economia internacional $^{1}$, representou uma conquista para a educação básica e para a formação de professores. O ciclo de avanços e retrocessos reflete dualidades dentro da área de formação docente, como, a separação entre teoria e prática, a fragmentação das habilitações e o perfil profissional, dentre outras questões. Os grupos representativos em disputa, sobretudo, a partir dos anos de 1980, contribuíram para as reflexões e lutas frente à formulação das diretrizes para os cursos de licenciaturas.

\footnotetext{
${ }^{1}$ Saviani (1997) aborda todo o processo de disputa em torno da consolidação da lei $\mathrm{n}^{\circ}$ 9.394/1996 (LDBEN).
} 
Nesse contexto, encontra-se o curso de Pedagogia que, sobretudo, a partir das Diretrizes Curriculares Nacionais (DCN), Resolução CNE/CP $n^{\circ} 1 / 2006$, consolidou projetos curriculares complexos, particularmente a partir da oferta de uma diversidade de componentes curriculares para atendimento às modalidades e funções relacionadas nessas DCN, que impactaram a consolidação de sua identidade. Adiciona-se à problemática, a substituição da Resolução CNE/CP n 2 de 2015 pela Resolução no 2 de 2019, que definiu as Diretrizes Curriculares Nacionais para a Formação Inicial de Professores para a Educação Básica e instituiu a Base Nacional Comum para a Formação Inicial de Professores da Educação Básica (BNC-Formação). Essa normativa mais recente incide diretamente na formação e certificação para o pedagogo atuar fora da sala de aula, como nas funções de gestão, cerceando a formação em Pedagogia somente para atuação no magistério.

Ademais, a atualização da matriz curricular tornou-se uma ação primordial para assegurar a identidade do curso de Pedagogia no que se refere a ampla atuação profissional.

Nesse sentido, o objetivo do presente trabalho é a análise dos principais marcos históricos sob a ótica política no campo da formação de professores que conformaram o curso de Pedagogia. A pesquisa é caracterizada pela abordagem qualitativa, utilizando os procedimentos de revisão de literatura e de pesquisa documental para fundamentação da temática e investigação empírica.

Na primeira seção do artigo, aborda-se a partir de marcos históricos, a trajetória do curso de Pedagogia no Brasil a partir, principalmente, da apreensão da política educacional voltada para a formação de professores. Já na segunda seção, busca-se discutir o processo de disputa de concepções de formação para o curso de Pedagogia e sua consolidação na política educacional mais recente por meio das diretrizes legais que incidem sob o curso. Por fim, nas considerações finais, enfatiza-se os desafios postos à identidade do curso de Pedagogia e sua dualidade formativa.

\section{Aspectos da trajetória política do curso de Pedagogia no Brasil sob a ótica histórica}

Desde a origem da Pedagogia na Grécia Antiga até as legislações educacionais, bem como as específicas para os cursos de licenciaturas no Brasil, a construção dessa área abarcou diferentes contribuições e papéis. De acordo Saviani (2009), a formação para o magistério tem sua manifestação visível nas primeiras décadas do século XIX, visto que a independência do Brasil marcou a preocupação com a instrução popular. $\mathrm{O}$ autor ainda destaca alguns marcos históricos que constituem a formação de professores no país, por exemplo, o movimento para a formação de professores, a partir da Lei das Escolas de Primeiras Letras, de 15 de outubro de 1827, que inaugurou o alinhamento das condições didáticas mínimas, também adotadas na Europa (SAVIANI, 2009). Ao encontro das novas políticas de educação do século XIX, conforme a demanda oriunda da universalização do ensino, foi necessário um maior volume de professores em exercício, assim ocorreu “" [...] a criação de Escolas Normais, de nível médio, para formar professores 
primários atribuindo-se ao nível superior a tarefa de formar os professores secundários" (SAVIANI, 2009, p. 148).

Segundo Rodrigues e Kuenzer (2007, p. 49), o século XX, mais especificamente as décadas finais, foi marcado pelas disputas no cenário educacional, quando também ascendeu a discussão da relevância dada a dimensão prática no sistema de ensino. Paralelamente, a produção acadêmica do país e do exterior "[...] privilegia a formação reflexiva do professor e a construção de competências profissionais, além de fazer crítica ao modelo da racionalidade técnica tradicionalmente adotado nos programas de formação de professores". As autoras discutem a desarmonia da teoria e da prática presente na vertente curricular voltada à preparação do professor para as etapas iniciais da educação básica e, consequentemente, a diminuição da área de estudo. Assim, fortes correntes intensificavam a crônica fragilidade na relação teoria e prática dentro do contexto da educação. A expansão das Escolas Normais por todo o país não expressava resultados satisfatórios no que tange a formação pedagógica dos professores, assim tornou-se relevante a abertura de novos ambientes como os Institutos de Educação, cometidos no Distrito Federal, por Anísio Teixeira, no ano de 1932, e em São Paulo, por Fernando de Azevedo, em 1933. Nesses respectivos locais foram fundadas universidades que tiveram a incorporação dos Institutos de Educação: São Paulo, em 1934; e Distrito Federal, em 1935 (SAVIANI, 2009).

O Decreto-Lei $\mathrm{n}^{\circ}$ 1.190/1939 transformou a, então, Faculdade Nacional de Filosofia, Ciências e Letras, em Faculdade Nacional de Filosofia com quatro seções, tendo contemplado em suas finalidades a formação de professores, técnicos e a pesquisa. O curso descrito nesse decreto-lei legalizou o primeiro curso de Pedagogia com duas habilitações e atuação distinta, a licenciatura para a docência e o bacharel para o trabalho técnico educacional (LIBÂNEO, 2010b). A regulamentação do curso de Pedagogia em 1939 promoveu a sistematização do currículo, mesmo fragmentado em bacharel e licenciatura, e evidenciou os esforços pela valorização das titulações em ensino superior, o que sugeriu o aprofundamento dos objetos de estudos. Entretanto, o famoso modelo 3+1 fortaleceu a divisão entre o técnico e o professor, entre o campo de estudo e de atuação profissional. Ainda, nos pareceres dos anos de 1960 permaneceram duas titulações, bacharel e licenciado, em cursos distintos, travando o progresso de uma definição específica para a Pedagogia. Para Libâneo (2010a, p. 124), “[...] observa-se aí uma tentativa de dar corpo aos estudos pedagógicos, mas não são especificadas as habilitações do bacharelado e persiste a separação rígida entre bacharelado e licenciatura".

Em 1961 foi promulgada a lei $\mathrm{n}^{\circ} 4.024 / 1961$ que fixou as Diretrizes e Bases da Educação Nacional. Fruto de intensos debates, essa lei promoveu ajustes na configuração do sistema educacional. Entretanto, mesmo destacando a fixação dos currículos mínimos, por exemplo, dos cursos superiores, bem como a autonomia das instituições educacionais na organização do ensino, os avanços demonstraram certa timidez. Para Tanuri (2000, p. 78), “[...] registre-se apenas a equivalência legal de todas as modalidades de ensino médio, bem como a descentralização administrativa e a flexibilidade curricular, que possibilitariam o rompimento da uniformidade curricular das escolas normais". A formação no curso de Pedagogia permaneceu sem alterações significativas após a 
LDBEN de 1961. No ano seguinte, o Conselho Federal de Educação instituiu o Parecer $n^{\circ}$ 251/1962 que tratou do curso de bacharel em Pedagogia e o Parecer n ${ }^{\circ}$ 292/1962 para o curso de licenciatura. Durante a década de 1960, o setor da educação subsistiu ao gerenciamento dos acordos entre o Ministério da Educação e Cultura (MEC) e a United States Agency for International Development (USAID). Seguindo as linhas de internacionalização do mercado, essa aliança promoveu novas reformulações na legislação através de apoio financeiro e investimento na educação para fins econômicos do sistema capitalista. Consequentemente, ocorreram novas reformas educacionais: a lei 5.540/1968, que abordou o ensino superior e desencadeou o Parecer CFE $n^{\circ}$ 252/1969, e, na sequência, a lei 5.692/1971, que alterou o antigo ensino básico para o ensino de primeiro e segundo graus (SOKOLOWSKI, 2013). As mudanças adquiridas nesses termos supracitados favoreceram positivamente a formação na área da Pedagogia, assim como permitiu as diferentes titulações na parte da gestão escolar. No entanto, Libâneo (2010a) reconhece que persistiu a dualidade entre a formação profissional do pedagogo e a formação para a docência.

Na década de 1980, o destaque entre os grupos organizados para pensar a definição central da área da Pedagogia foi a Comissão Nacional de Reformulação dos Cursos de Formação de Professores (CONARCFE), criada em 1983 e grande responsável pelas propostas que criaram as Diretrizes Curriculares Nacionais de 2006, sob a jurisdição do Conselho Nacional de Educação (CNE). Posteriormente, transformou-se na renomada Associação Nacional de Formação dos Profissionais da Educação (ANFOPE) (SOKOLOWSKI, 2013). A representação da defesa da unificação do curso de Pedagogia, assim como a definição de uma base comum nacional para os cursos de todas as licenciaturas, estava agora representada na figura da ANFOPE e demais associados, como parte da bandeira da reformulação dessas categorias.

De acordo com Sokolowski (2013), a partir dos anos de 1990, foram retomadas iniciativas para adoção subserviente das diretrizes de modelos externos à educação brasileira, que culminaram em novas tendências nos setores educacionais e na relação educação-mercado-produção. "A década de 1990 marcou o avanço do neoliberalismo no Brasil e no mundo. Isto trouxe profundas mudanças no campo educacional $\mathrm{e}$ consequentemente no processo de formação de pedagogos" (SOKOLOWSKI, 2013, p. 88). Esse ideário foi incorporado nas políticas dos governos desse período, de modo a consolidar proposições baseadas em competências profissionais como assertivas à competitividade do mercado de trabalho. Frigotto (1998) chama a atenção para o retorno das tendências vinculadas ao conservadorismo que, ao passo das políticas neoliberais de livre mercado e Estado Mínimo, comprometeram os direitos constitucionais. A mercê das relações estreitas entre educação e trabalho nesses termos, o sistema educacional brasileiro absorve as condições internacionais de mercado e produção como parte também da globalização. Nesse sentido, o autor aponta um processo formativo com "[...] habilidades básicas no plano do conhecimento, das atitudes e dos valores, produzindo competências para gestão da qualidade, para a produtividade e competitividade e, consequentemente, para a empregabilidade" (FRIGOTTO, 1998, p. 45). A própria LDBEN no 9.394/1996 foi uma conquista indolente, assinada pelo então presidente Fernando Henrique Cardoso no cenário neoliberal do país, que promoveu de certa forma avanços, mas, na contramão, trouxe elementos contraditórios para os fins de regulação e 
controle do sistema educacional e formativo. Entretanto, a promulgação da LDBEN 9.394/1996 também marcou o panorama histórico da educação brasileira, principalmente no que tange a universalização do direito à educação e a reorganização das etapas da educação básica.

Em conformidade com os artigos da LDBEN n ${ }^{\circ}$ 9.394/1996 foi homologado o Parecer CNE/CP n 9/2001. O Parecer definiu as Diretrizes Curriculares Nacionais para a formação de Professores da Educação Básica, em nível superior, e foi criado a partir de reflexões dos recorrentes impasses na formação de professores. A proposta "[...] apresenta princípios orientadores amplos e diretrizes para uma política de formação de professores, para sua organização no tempo e no espaço e para a estruturação dos cursos" (BRASIL, 2001, p. 6), a partir do mesmo, estabeleceu-se normas exclusivas para as licenciaturas deixando à margem os currículos anteriores e possíveis divergências com o bacharel. No ano seguinte ao Parecer, entraram em vigor a Resolução CNE/CP nº 1/2002, que instituiu Diretrizes Curriculares Nacionais para a Formação de Professores da Educação Básica, em nível superior (licenciatura e graduação plena), e a Resolução $\mathrm{CNE} / \mathrm{CP} \mathrm{n}^{\mathrm{o}}$ 2/2002, que instituiu a duração e a carga horária dos cursos de licenciatura, de graduação plena e de formação de professores da Educação Básica em nível superior.

\section{A política curricular enquanto preocupação estratégica na identidade e formação profissional}

A ANFOPE seguiu suas pautas em torno da reformulação dos cursos de Pedagogia e demais licenciaturas, composta por uma base comum que atendesse aos diversos contextos e a centralidade na docência. Um tópico abordado no documento do X Encontro Nacional realizado em Brasília, no ano 2000, tratava da unidade entre teoria e prática. Apesar da expressividade da proposta liderada pela ANFOPE, a oposição desenhava fortes críticas ao modelo de unificação da formação para a docência e do pedagogo não docente. Na voz do professor José Carlos Libâneo ecoou um posicionamento contrário a asserção da ANFOPE, e em diversas publicações trouxe sua perspectiva de formação para os cursos de graduação em Pedagogia: o pedagogo stricto sensu. O autor e outros adeptos se posicionam tendo em vista uma formação centrada na pesquisa e na definição do objeto de estudo - as problemáticas da educação - não constituindo assim a exclusividade da docência para preservar a identidade da área da Pedagogia e a diferenciação das demais licenciaturas. Convicto, Libâneo (2010b, p. 45) defende que "[...] o curso de Pedagogia é o que forma o pedagogo stricto sensu, isto é, um profissional não diretamente docente que lida com fatos, estruturas, processos, contextos, situações, referentes à prática educativa em suas várias modalidades e manifestações".

Em meio às tensões entre as linhas opostas para a (re)formulação dos novos sentidos para a área da Pedagogia, foram enfim instituídas no ano de 2006, através da Resolução CNE/CP nº 1/2006, as DCN para o curso de Pedagogia. Dentre as mudanças estabelecidas, o artigo 7 redefine a carga horária mínima para 3.200 horas e o artigo 4 aponta a docência como base da formação (BRASIL, 2006). Souza e Silva (2018, p. 396) afirmam que, o curso "[...] passa a ser uma licenciatura, na qual a docência é o eixo principal e as antigas habilitações cedem espaço para uma formação unificada na 
pluralidade do trabalho do pedagogo, isto é, do trabalho desse licenciado em Pedagogia". Diante dessa última colocação, ocorreu uma polarização em torno da unificação das habilitações em prol de uma nova caracterização da formação e da atuação.

Em contrapartida ao fixado na Resolução, Libâneo (2010a) entende que a Pedagogia recuou no que diz respeito à afirmação do campo de estudo e pesquisa enquanto ciência da educação, quando reforça o pedagogo como sinônimo de docente do ensino infantil e fundamental. Essa função seria apenas mais uma dentre as muitas atribuições da abrangência do campo ligado ao processo educativo.

As DCN para o curso de graduação em Pedagogia delinearam, mesmo que de forma ampla, o campo de formação e atuação do pedagogo, necessariamente urgente diante do panorama histórico apresentado. Os cursos criados desde então, assumiram tais premissas em seus projetos pedagógicos e, naturalmente, enfrentaram e ainda enfrentam as implicações dessas questões históricas em contraste com a concretização da identidade da Pedagogia. Os cursos de graduação em Pedagogia originários a partir de 2006 acumulam críticas em oposição a descaracterização do pedagogo, posto a exaltação da docência nos currículos. A ANFOPE assegura que a base comum nacional, que não se confunda com a base nacional comum da educação básica e a formação comum dos professores instituídas pelo MEC, na contramão do processo de autonomia educacional, "[...] deve enfatizar a indissociabilidade entre ensino, pesquisa e extensão na estruturação dos cursos de formação dos educadores" (ANFOPE, 2006, p. 11). Em seu ensaio, Oliveira (2010, p. 247) ratifica a proposição das diretrizes da Pedagogia em prol da sistematização de cursos com "[...] aprofundamento de estudos sempre a partir da formação comum da docência na Educação Básica".

Em 2015, a Resolução CNE/CP n ${ }^{\circ} 2$ instituiu as Diretrizes Curriculares Nacionais para a Formação Inicial e Continuada em Nível Superior de Profissionais do Magistério para a Educação Básica. De acordo com o artigo 5:

\begin{abstract}
A formação de profissionais do magistério deve assegurar a base comum nacional, pautada pela concepção de educação como processo emancipatório e permanente, bem como pelo reconhecimento da especificidade do trabalho docente, que conduz à práxis como expressão da articulação entre teoria e prática e à exigência de que se leve em conta a realidade dos ambientes das instituições educativas da educação básica e da profissão (BRASIL, 2015).
\end{abstract}

Na sequência, nos incisos desse mesmo artigo, vêm descritos as funcionalidades atribuídas aos egressos após a conclusão dessa formação. Mantendo os núcleos de estudos da matriz curricular e a carga horária de 3.200 horas da formação inicial em nível superior já identificados nas legislações vigentes, a resolução não implicou mudanças significativas nos cursos de Pedagogia em andamento. O principal prejuízo para as áreas ligadas à gestão escolar, reconhecida nos cursos de Pedagogia, veio com a revogação dessa resolução através da mais nova Resolução CNE/CP nº 2/2019:

Artigo 22. A formação para atuar em Administração, Planejamento, Inspeção, Supervisão e Orientação Educacional para a Educação 
Básica, nos termos do art. 64 da LDB, ou com centralidade em ambientes de aprendizagens e de coordenação e assessoramento pedagógico, pode-se dar em: I - cursos de graduação em Pedagogia com aprofundamento de estudos nas áreas de que trata o caput e que possuam uma carga horária mínima de 3.600 (três mil e seiscentas) horas; e II - cursos de especialização lato sensu ou cursos de mestrado ou doutorado, nas mesmas áreas de que trata o caput, nos termos do inciso II do art. 61 da LDB (BRASIL, 2019).

Claramente, a exigência da carga horária descrita no primeiro inciso descaracteriza os cursos de Pedagogia alinhados com as DCN de 2006 e com a Resolução $\mathrm{CNE} / \mathrm{CP} \mathrm{n}^{\circ} 2 / 2015$, que regulamentava 3.200 horas para os cursos de licenciaturas. Ambas apresentam grandes conquistas no campo da formação de professores a nível nacional em contraposição a mais recente normativa, o que denota um retrocesso para a área da Pedagogia.

Libâneo e Pimenta (1999, p. 248 e 249), observando a projeção das DNC de 2006 para o curso de Pedagogia, já apontavam, previamente, dentre outras lacunas, "[...] o inchaço do currículo, [...], e o empobrecimento na oferta de disciplinas (já que, para atender ao menos seis das áreas de atuação previstas, será necessário reduzir o número de disciplinas, a fim de respeitar o total de $3.200 \mathrm{~h}$ do curso)". Isto é, um currículo volumoso em termos de variedade de conhecimento, com pouco aprofundamento nas disciplinas da mesma área de estudo.

Em contrapartida, Souza e Silva (2018) compreendem que, as DCN para o curso de Pedagogia e a Resolução CNE/CP n ${ }^{\circ}$ 2/2015 indicaram uma articulação entre as licenciaturas e a educação básica e a tentativa de romper com a segmentação dos saberes. Sendo assim "[...] é necessário pensar em uma ampliação da base comum pedagógica da formação dos licenciados, que contemple tanto disciplinas de fundamentos como as demais disciplinas de modo a compor o currículo na sua pluralidade de demandas para a docência" (SOUZA e SILVA, 2018, p. 395). Com uma visão mais conservadora da base da formação e função do pedagogo, Libâneo (2010b) reitera a consistência atemporal do sentido pedagógico frente às transformações contemporâneas das/nas práticas educativas, haja vista, a resistência a criação da nova organização curricular. O autor sintetiza o campo da Pedagogia em estudos científicos e filosóficos da educação e conhecimentos teóricos e práticos. Sendo os conhecimentos científicos e filosóficos da educação parte do núcleo básico da formação do pedagogo junto com outra parte de conhecimentos específicos; e os conhecimentos técnico-profissionais específicos. Já os princípios defendidos pela ANFOPE reiteram que:

Este movimento de resistência articula-se ao movimento da investigação e da pesquisa na área educacional, no debate das concepções e do estatuto científico da educação e da pedagogia, na definição da identidade dos cursos e dos profissionais da educação, em suas interfaces com a sociedade, as práticas sociais e a escola e os diferentes espaços e tempos educativos, campos em constante transformação (ANFOPE, 2006, p. 28). 
Assim, nas DNC de 2006, para o curso de Pedagogia, estava assegurada a autonomia das IES (artigo 6 e inciso II), que garantia o direcionamento dos campos de aprofundamento profissional de acordo com o projeto pedagógico e o contexto de inserção das instituições. Entretanto, o que se observa na nova Resolução n ${ }^{\circ}$ 2/2019 é a imposição de competências e habilidades para formação de professores padronizada e adequada a Base Nacional Comum Curricular da Educação Básica (BNCC), com caráter estritamente instrumental dissociado da relação teoria e prática. Em relação à formação para habilitar o exercício do pedagogo nas áreas de gestão escolar, os cursos de graduação em Pedagogia sofrerão ajustes de carga horária curricular.

Franco, Libâneo e Pimenta (2011, p. 61) consideram que os campos que integram a atuação profissional do pedagogo ultrapassam a restrita formalidade escolar abarcando o espaço não-formal e informal, ou seja, "[...] toda atividade docente é atividade pedagógica, mas nem toda atividade pedagógica é necessariamente atividade docente". No cenário atual tal perspectiva pode ser subsumida pelos fundamentos da Resolução ${ }{ }^{\circ}$ 2/2019 para justificar o aumento da carga horária, que, na verdade, pelo caráter instrumentalista dessa resolução não significa de fato o que os autores em questão defendem para a formação do pedagogo.

Cabe salientar que o processo divergente, mas profícuo, entre a concepção atribuída ao docente e ao pedagogo, legitimada em duas correntes fortemente conceituadas, que ainda dividem opiniões e adeptos e influenciam as discussões dentro dos próprios cursos alinhados às DCN de 2006, não se alinham aos pressupostos da Resolução n ${ }^{\circ}$ 2/2019.

Por fim, reitera-se ainda no contexto atual o que Oliveira (2010), ao analisar as definições da Resolução CNE/CP n 1/2006 quanto à ação do pedagogo na escola e nos espaços prontificados a receber as práticas pedagógicas, aponta:

O que se pode perceber é uma amplitude da atividade docente. Então definir o campo de atuação do pedagogo é definir o campo de atuação dos docentes da educação infantil e das séries iniciais, que não se restringirá ao trabalho docente, mas alcançará o trabalho pedagógico. Busca-se com esse movimento superar a dicotomia professor $\mathrm{x}$ especialistas: nem circunscrever a formação docente num conjunto de metodologias de ensino ou conteúdos específicos para a docência, nem fomentar a fragmentação já prevista desde 1969 - com as diversas habilitações - caracterizando na formação dos especialistas (OLIVEIRA, 2010, p. 247).

No mesmo sentido, Cruz e Arosa (2014) assinala o desafio da formação para diversidade do campo profissional do egresso, atendendo as especificidades do professor e do gestor, somada as implicações das legislações educacionais.

De forma divergente, as reformas em curso apresentam uma proposta que direciona a formação de professores como treinamento, para execução de propostas que colocam em prática uma escola instrumentalizadora da classe trabalhadora para um determinado tipo de sociedade. Sendo assim, os professores precisam ser formados com 
uma função específica que prescinde da autonomia de pensamento e do controle sobre o próprio trabalho, por meio de uma formação circunscrita ao trabalho com um currículo mínimo, não mais como ponto de partida, mas como ponto de chegada tanto para alunos como para os professores. Ao curso de Pedagogia, não somente poderá ampliar o dilema da relação teoria e prática, mas projeta reduzi-lo a supervalorização da dimensão técnica dos conhecimentos pedagógicos para instrumentalização nos termos da BNCC da Educação Básica.

\section{Considerações finais}

A formação de professores configura historicamente um cenário de muitas conquistas e contradições no processo de disputa na política nacional. Na conjuntura, a área de educação tem sido enfraquecida devido aos constantes retrocessos na política educacional.

Assumir o papel de docente desperta, entre as diversas tarefas, a responsabilidade de prezar pela melhoria da educação, através de políticas públicas efetivas de acesso, permanência e formação. Para tanto, é essencial a revisitação dos conflitos históricos para a compreensão do contexto atual.

Em relação ao campo em si da Pedagogia, esse trabalho buscou apontar os estudos relativos ao seu estatuto científico e o processo dual da formação profissional. Diante de duas concepções opostas relativas à identidade do curso, busca-se as questões implícitas e significativas para o debate, a fim de contribuir com a reflexão atual sobre a função social, pedagógica e humana do pedagogo frente as diretrizes recentes para a área.

A alteração que a Resolução CNE/CP n 2/2019, a respeito da habilitação para a gestão escolar, retirando tal incumbência do curso de Pedagogia, intensifica o debate, mas com um sentimento de recomeçar um caminho já percorrido. Isso porque antes da especificidade do trabalho pedagógico preconizado nas DCN de 2006, as "especialidades" em cursos de pós-graduação descaracterizavam em grande medida a identidade da Pedagogia. A restrição, agora, afirmada na Resolução CNE/CP nº 2/2019, limita o curso de Pedagogia à formação de professores. Perde-se a amplitude das modalidades formativas, a investigação científica do objeto de estudo para além da sala de aula. Consequentemente, reascende a desvalorização da formação para o magistério nas primeiras etapas da educação básica em nível superior, que enfatiza a relação entre a teoria e a prática (práxis docente). Já que a formação em nível médio na modalidade normal também habilita para as mesmas etapas, com uma formação voltada para uma prática pragmática, desvinculada da integração entre ensino, pesquisa e extensão desenvolvida nas universidades.

As concepções de formação na visão da ANFOPE e do grupo composto por Libâneo e outros professores/pesquisadores revelam importantes contribuições acerca da formação e atuação do pedagogo, que não fazem sentido na configuração atual da política de formação para o curso de Pedagogia. Portanto, o grande desafio é manter acessa a resistência e a reflexão crítica do próprio trabalho e da identidade do pedagogo, 
prioritariamente, nesses tempos difíceis e sombrios para a educação brasileira e para a docência.

\section{Referências}

ANFOPE. Documento Final: XIII Encontro Nacional. Faculdade de Educação Unicamp, 55pp. 2006. Disponível em: https://www.anfope.org.br/wpcontent/uploads/2018/05/13\%C2\%BA-EncontroDocumento-Final-2006.pdf. Acesso em 18 fev. 2021.

BRASIL. Lei $n^{\circ}$ 4024/1961, de 20 de dezembro de 1961. Fixa as Diretrizes e Bases da Educação Nacional. Disponível em: https://www2.camara.leg.br/legin/fed/lei/19601969/lei-4024-20-dezembro-1961-353722-publicacaooriginal-1-pl.html. Acesso em 18 fev. 2021.

BRASIL. Lei $n^{\circ}$ 9.394/1996, de 20 de dezembro de 1996. Estabelece as Diretrizes e Bases da Educação Nacional. Disponível em: http://www.planalto.gov.br/ccivil_03/leis/19394.htm. Acesso em 13 jan. 2021

BRASIL. Parecer $C N E / C P n^{\circ}$ 9/2001. Diretrizes Curriculares Nacionais para a Formação de Professores da Educação Básica, em nível superior, curso de licenciatura, de graduação plena. Brasília-DF, 08 de maio de 2001. Disponível em: http://portal.mec.gov.br/cne/arquivos/pdf/009.pdf. Acesso em: 14 jan. 2021.

BRASIL. Resolução CNE/CP $n^{\circ} 1$, de 18 de fevereiro de 2002. Institui Diretrizes Curriculares Nacionais para a Formação de Professores da Educação Básica, em nível superior, curso de licenciatura, de graduação plena. Diário Oficial da União, Brasília, 9 de abril de 2002. Seção 1, p. 31. Republicada por ter saído com incorreção do original no D.O.U. de 4 de março de 2002. Seção 1, p. 8.

BRASIL. Resolução CNE/CP $n^{\circ}$ 2, de 19 de fevereiro de 2002. Institui a duração e a carga horária dos cursos de licenciatura, de graduação plena, de formação de professores da Educação Básica em nível superior. Diário Oficial da União, Brasília, 4 de março de 2002. Seção 1, p. 9.

BRASIL. Resolução CNE/CP $n^{o} 1$, de 15 de maio de 2006. Institui Diretrizes Curriculares Nacionais para o Curso de Graduação em Pedagogia, licenciatura. Diário Oficial da União, seção 1, p. 11. Brasília-DF, 16 de maio de 2006.

BRASIL. Resolução CNE/CP $n^{o} 2$, de $1^{o}$ de julho de 2015. Define as Diretrizes Curriculares Nacionais para a formação inicial em nível superior (cursos de licenciatura, cursos de formação pedagógica para graduados e cursos de segunda licenciatura) e para a formação continuada. Brasília-DF: MEC. Diário Oficial da União, 2 de julho de 2015, seção 1 , p. 8-12. 
BRASIL. Resolução CNE/CP $n^{o}$ 2, de 20 de dezembro de 2019. Define as Diretrizes Curriculares Nacionais para a Formação Inicial de Professores para a Educação Básica e institui a Base Nacional Comum para a Formação Inicial de Professores da Educação Básica (BNC-Formação). Brasília-DF: MEC. Diário Oficial da União de 10/2/2020, seção 1, p. 87 a 90.

CRUZ, Gisele Barreto da; AROSA, Armando de Castro de Cerqueira. A formação do pedagogo docente no curso de Pedagogia. Revista Educação e Cultura Contemporânea, v. 11, n.26, 2014.

DERMEVAL, Saviani. A nova lei da educação-trajetória: limites e perspectivas. Campinas: Autores Associados, 1997.

FRANCO, Maria Amélia Santoro; LIBÂNEO, José Carlos; PIMENTA, Selma Garrido. As dimensões constitutivas da Pedagogia como campo de conhecimento. Revista UEMG: Educação em foco, ano 14, n. 17, p. 55-78, julho 2011.

FRIGOTTO. Educação, crise do trabalho assalariado e do desenvolvimento: teorias em conflito. In: FRIGOTTO, Gaudêncio (org.). Educação e crise do trabalho: perspectiva de final de século. Petrópolis, RJ: Vozes, p. 25-54, 1998.

LIBÂNEO, José Carlos. Pedagogia e pedagogos: inquietações e buscas. Editora da UFPR: Educar, Curitiba, n. 17, p. 153-176. 2001.

LIBÂNEO, José Carlos. Educação: Pedagogia e didática- O campo investigativo da pedagogia e da didática no Brasil: esboço histórico e buscas de identidade epistemológica e profissional. In: LIBÂNEO, José Carlos. Pedagogia e pedagogos, para quê? São Paulo, Cortez, $12^{\mathrm{a}}$ ed., cap. IV, p. 105-157, 2010a.

LIBÂNEO, José Carlos. Que destino os educadores darão à Pedagogia. In: LIBÂNEO, José Carlos. Pedagogia e pedagogos, para quê? São Paulo, Cortez, $12^{\mathrm{a}}$ ed., cap. II, p. 43$68,2010 \mathrm{~b}$.

LIBÂNEO, José Carlos; PIMENTA, Selma Garrido. Formação de profissionais da educação: Visão crítica e perspectiva de mudança. Educação \& Sociedade, ano XX, ${ }^{\circ}$ 68, dezembro de 1999.

OLIVEIRA, Leandra Martins de. Políticas educacionais na formação da professora dos anos iniciais do Ensino Fundamental em cursos de licenciatura. Ensaio: aval. pol.públ. Educ., Rio de Janeiro, v. 18, n. 67, p. 235-252, abr./jun. 2010.

RODRIGUES, Marli de Fátima; KUENZER, Acácia Zeneida. As diretrizes curriculares para o Curso de Pedagogia: uma expressão da epistemologia da prática. Olhar de Professor, vol. 10, n. 1, p. 35-62, 2007. 
SAVIANI, Dermeval. Formação de professores: aspectos históricos e teóricos do problema no contexto brasileiro. Revista Brasileira de Educação, v. 14, n. 40, jan./abr. 2009.

SOKOLOWSKI, Maria Teresa. História do curso de Pedagogia no Brasil. Comunicações: Piracicaba, ano 20, n. 1, p. 81-97, jan/jun. 2013. Disponível em: http://dx.doi.org/10.15600/2238-121X/comunicacoes.v20n1p81-97. Acesso em : 26 dez. 2019.

SOUZA, Silvério A. M. Soares de; SILVA, Dagmar de Mello e. Professor ou Pedagogo, Uma Breve Reflexão. RevistAleph, n 31, p. 392-403, ISSN 1807-6211. Dez de 2018.

TANURI, Leonor Maria. História da formação de professores. Revista Brasileira de Educação, no 14, p. 61-88, mai/ago, 2000.

* Renata Loiza Alcântara Soares é professora efetiva da Rede Municipal de Volta Redonda/RJ. Licenciada em Educação Física e em Pedagogia pela Universidade Federal Rural do Rio de Janeiro (UFRRJ). Especialista em Educação Física Escolar com ênfase em Inclusão, pela Faculdade de Educação São Luís.

E-mail: renataas@yahoo.com.br

ORCID: https://orcid.org/0000-0001-8727-6226

** Viviane de Souza Rodrigues é professora na Universidade Federal Rural do Rio de Janeiro (UFRRJ). Doutora e Mestre em Educação pela Universidade Federal Fluminense (UFF). Pesquisadora do Grupo de Pesquisas sobre Trabalho, Política e Sociedade (GTPS/UFRRJ).

E-mail: vivi srodrigues@yahoo.com.br

ORCID: https://orcid.org/0000-0002-7327-9247 